Student Success

ISSN: 2205-0795

Volume 9, Issue 4, pp. 41-51

December 2018

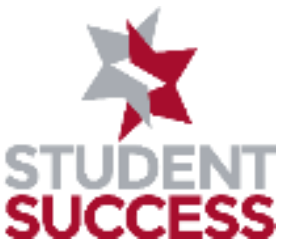

\title{
Exploring the first-year experience in a diverse population: Using participatory action research to explore strategies to support student transition into fast- track undergraduate degree programs
}

\author{
Greg Rickarda, Marguerite Brambleb; Hazel Maxwella; Rochelle Einbodenc; Sally Farringtona; \\ Richard Say ${ }^{a}$, Chin-Liang Beha, Grace Stankiewicz ${ }^{a}$, Craig Campbella and Caroline Yeh ${ }^{\mathrm{a}}$
}

University of Tasmania, Sydney, Australia

Charles Sturt University, Bathurst, Australia

The University of Sydney, Sydney, Australia

\section{Abstract}

As the cohort of students in Australian universities become increasingly diverse, attention to ensuring their success is an emerging issue of social justice in tertiary education. Navigating transitions through the student journey is crucial to their success. Exploring and responding to the needs of a cohort of firstyear students is the focus of this research. Using a participatory action approach, this project aimed to discover what is meaningful for first-year students, by exploring how students experienced the processes of admission, enrolment, commencement, and learning and teaching in two fast-track and one online health degrees. Nine students were partnered with nine academics for a six-month period. The analysis offers insights into equity issues in relation to the institution's admission processes, the quality of support and engagement from academics to students when transitioning to university life, and how students find their 'place'. Strategies to support the transition process for first-year students are identified and discussed.

Please cite this article as:

Rickard, G., Bramble, M., Maxwell, H., Einboden, R., Farrington, S., Say, R., ... Yeh, C. (2018). Exploring the first-year experience in a diverse population: Using participatory action research to explore strategies to support student transition into fast-track undergraduate degree programs. Student Success, 9(4), 41-51. doi: 10.5204/ssj.v9i4.653

This article has been peer reviewed and accepted for publication in Student Success. Please see the Editorial Policies under the 'About' section of the Journal website for further information.

$(0)$ This work is licensed under a Creative Commons Attribution 4.0 International Licence. As an open access journal, articles are free to use with proper attribution. ISSN: 2205-0795 


\section{Student engagement and retention}

In Australia, and internationally, there is increasing evidence that the first year of study is critical to student engagement and retention (Briggs, Clark, \& Hall, 2012). Student retention relates to successful transition into a degree program (James Cook University, 2017). The 'student lifecycle' involves multiple transitions: identification of the course and institution at which students wish to study; navigating admissions, enrolment, and orientation; course and unit induction; development of learning strategies; and finally, the completion of the degree. Successful transition requires a 'capacity to navigate change' (Brook, Fergie, Maeorg, \& Michell, 2015, p. 16). First-year students are most vulnerable to withdrawal early in their first semester (Wilson et al., 2016), thus initial experience sets the stage for successful transition. Retention is improved when student needs are met; including a high quality academic experience with good faculty, peer and social support (Wilson et al., 2016).

First-year students grapple with 'culture shock' as they experience a loss of confidence and lack of tacit knowledge of learning expectations within the new environment. Academic transition requires students to develop autonomous academic skills alongside the course curriculum. The transition from teacherled early learning experiences, to autonomous learning at university can be challenging, unless it is supported by academics through group interactions and quality feedback on assessments (Briggs et al., 2012). Attention to the first-year experience has resulted in the development of a transition pedagogy in higher education and tailored strategies focused on this initial transition (Kift, 2009; Kift, Nelson, \& Clarke, 2010).

Hughes and Smail (2015) identified three key areas of focus as important during the first few weeks at university: development of social support networks; the student's psychological adjustment and positive wellbeing; and a well- paced induction that avoids complex administration. While early research focused on institutional and student guidelines to support transition (Tinto, 1987), recent research suggests transition requires more than institutional activities (Gale \& Parker, 2014), and includes students creating a new identity and a sense of belonging (Briggs et al., 2012).

Student identity and knowledge cannot be sufficiently built through formal induction, but rather through formation of 'communities of practice' (Wenger \& Snyder, 2000) amongst students (Christie, Tett, Cree, Hounsell, \& McCune, 2008). Students experience less anxiety during transition, if they feel they 'fit in' (Briggs et al., 2012). Successful transition of a student into the university culture requires social integration though supportive peer-topeer interactions and local role models, which are especially important as the 'social situatedness' of learning is appreciated (Christie et al., 2008). Students require deliberate and thoughtful support for their academic and social needs, and they need the opportunity to engage in learning relationships and environments which are built on respect, trust, connectedness and inclusivity (Kift, 2015).

Universities are seeking to expand equity and access, recruiting international and mature age students, including a growing proportion of students from culturally and linguistically diverse (CALD) backgrounds, low socioeconomic sectors, and first-in-family. These students frequently enter the institution naïve, with little support choosing courses or units strategically, and with large gaps between their experience and expectations. The lack of guidance to navigate the system translates into challenges with transition (Briggs et al., 2012).

Transition models abound, with Kurt Lewin's 1947 seminal work establishing the scientific foundation of understanding how individuals and groups respond and adapt to ever-changing environments (Burnes, 2004). Transitions are 
evident throughout the lifespan, shaped by social roles, education, employment, and health. Any stimulus provides the opportunity or challenge, for adaptation and growth. Bridges (1986) describes transition as letting go of the old (disengagement, dis-identification and disenchantment), experiencing a period in the neutral zone (disorientation, identity disintegration) and finally experiencing a new beginning (forming a new identity). How each stage is experienced and its duration depends on whether someone considers themselves a 'migrant' (permanent relocation) or a 'sojourner' (temporary dislocation) (Ward, Furnham, \& Bochner, 2005, p. 142). In this study, student transition parallels a migrant or permanent relocation identity shift, rather than sojourner. Even though students only spend a few years at university, achieving a higher education qualification involves a 'whole of life' identity change (becoming something - doctor, engineer, lawyer, accountant, etc.), 'taking on' the values, ethics and behaviours (persona) of their new discipline rather than an isolated experience of a few years (Gale \& Parker, 2014). The student is a migrant into the world of the 'educated'.

Student connection with the institution is critical to their engagement with their studies, academic staff and students/peers, and the university life/student experience generally. With the increase in diversity amongst student cohorts, student-oriented strategies that acknowledge students' lives, including education, linguistic and social-cultural backgrounds, income generation, family commitments and perception about alignment of their university learning to future career success, are needed more than ever (James Cook University, 2017; Nelson, Duncan, \& Clarke, 2009). The key challenge for a higher education institution is how best to engage with the diverse range of students in a manner that meets their academic, discipline, cultural and social needs. A 'one-size-fits-all' approach is not sufficient.

This study aims to better understand, and respond to, specific challenges faced by a diverse cohort of first-year students in fasttrack $^{1}$ two-year bachelor degree courses at a small urban satellite campus. ${ }^{2}$ This study uses a Participatory Action Research model of partnerships between academics and students, building on an earlier project by the team (see Bramble et al. 2018), and supported by an understanding of a relationship between social inclusion and positive transitions in the existing literature (Briggs et al., 2012; Christie et al., 2008; Kift, 2015). Our research explores strategies to support first-years' transition into the student role with the aim of increasing success and retention across this diverse cohort. We do this by asking two questions: what is meaningful for the first-year student when transitioning to higher education to achieve success? and, what guidance and support do first-year students need to optimise their learning and transition? Underpinning this research are the principles and intentions to support equity, social justice and social capital, which lay the foundations for facilitating a sense of engagement, support and belonging (Smith, 2007). Our paper reports the themes that have emerged and our proposed recommendations for improvement in support, both from academics and the institution.

\section{Methodology and study design}

A Participatory Action Research (PAR) design was used to build a sense of shared ownership in the research process, to find practical solutions to the pressing issues of concern and to aid the flourishing of the individual and

\footnotetext{
${ }^{1}$ Fast-track: six semesters of an undergraduate degree usually facilitated over three years, are facilitated over two years, (three semesters per year).

${ }^{2}$ The satellite campus is in another state from the main institution, situated in an urban setting that is geographically remote from the main university campus.
} 
student community (Heron \& Reason, 1997). This approach was aimed at fostering staff collaboration, generating team solidarity, enriching student/staff cohesion, and fostering first-year student engagement on campus (Polit \& Beck, 2008).

Nine student participants were recruited from the first-year cohort of the Bachelor of Health and Community Care, Nursing, and Paramedicine who commenced their studies in February 2017. For the purposes of pairing with academic staff, three students from each course were recruited. The academic participants consisted of the research team who are all staff of the Faculty of Health and Medicine. There were nine academic participants: between 35 65 years of age; four males and five females, from a range of diverse professional, academic, cultural and linguistic backgrounds.
The PAR (see Figure 1) focused on three action cycles -1 ) discovery 2) reflection and 3) review.

The discovery cycle (workshop one) involved a two-hour focus group with all student participants and two of the academic staff, using semi-structured questions. The questions (see Table 1) helped guide the participants to contemplate their initial higher education experiences, identified their needs as students, and what they believed could promote an inclusive and engaged campus community. The conversation was not restricted to these questions only but allowed to flow where the facilitators noticed energy in the group.

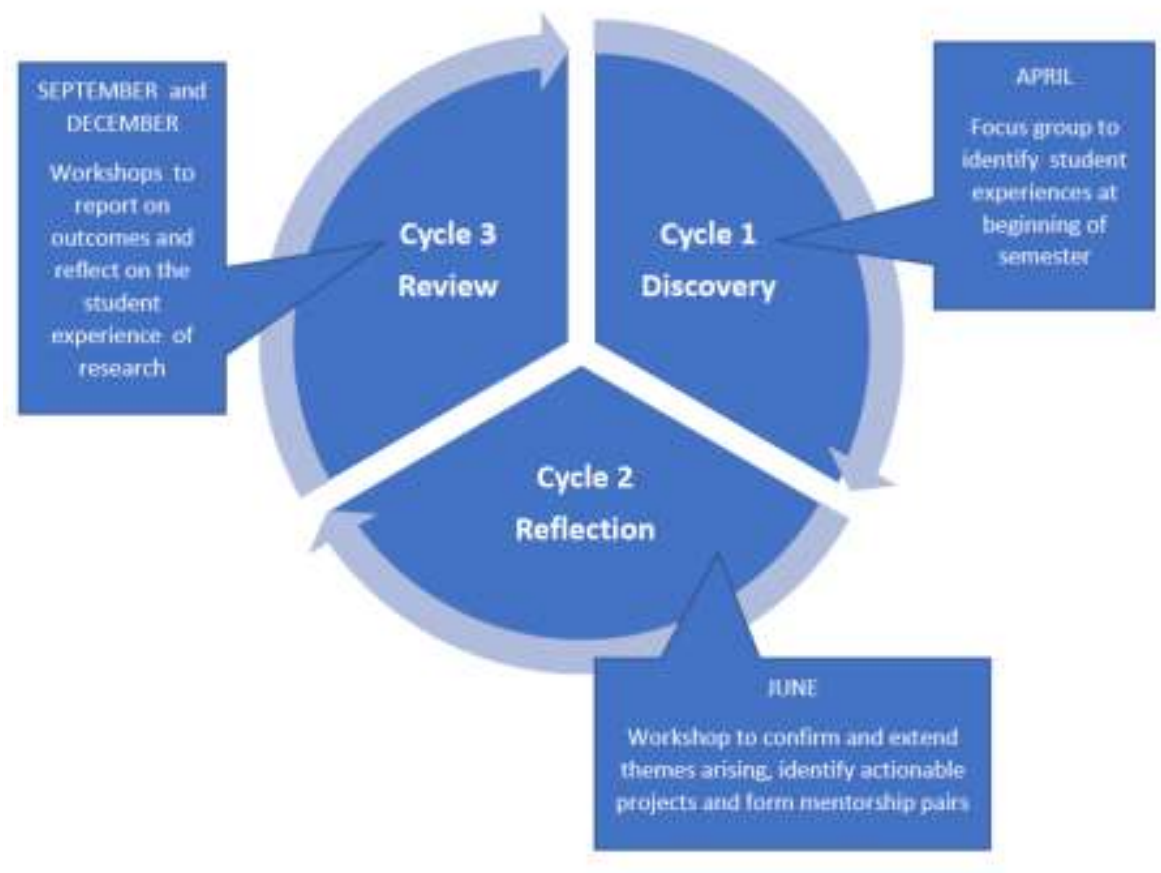

Figure 1. The Action Research Cycle 


\section{Table 1}

\section{Focus Group questions}

\begin{tabular}{|c|c|}
\hline 1 & What does it mean to be a university student? \\
\hline 2 & What were your expectations? \\
\hline 3 & $\begin{array}{l}\text { Did your experience/reality match your } \\
\text { expectations? }\end{array}$ \\
\hline 4 & $\begin{array}{l}\text { How was the transition to university student } \\
\text { for you? }\end{array}$ \\
\hline 5 & $\begin{array}{l}\text { What were the most important aspects/parts } \\
\text { of the university transition for you? }\end{array}$ \\
\hline 6 & What were the best aspects for you? \\
\hline 7 & What were the worst aspects for you? \\
\hline 8 & What are the challenges for you? \\
\hline 9 & How can they be improved? \\
\hline 10 & $\begin{array}{l}\text { What could the university do to improve the } \\
\text { transition to student for you? }\end{array}$ \\
\hline
\end{tabular}

The reflection cycle started with academics analysing the focus-group transcript for themes. These themes were presented at the second workshop with all participants. We formed three small groups ( $\mathrm{n}=6$ per group) to review and extend the themes, from which initial actionable projects were identified. Academicstudent dyads were then established to work on the actionable projects. Between Workshop 2 and 3, 'community of practice' (Wenger \& Snyder, 2000) groups spontaneously emerged around the three key actionable projects. Dyads or community of practice groups engaged in ad hoc one-to-one meetings and small group discussions. Each dyad agreed their own level of engagement based on individual workload and project requirements. These discussions focused on their chosen actionable project, exploring challenges and possible solutions. Pairs or groups were encouraged to document their individual meetings and reflections for use as part of the data collection. The review cycle involved two, two-hour workshops, during which staff and student participants reflected in small groups on their communities of practice (dyads), building capacity in improving student connection, engagement and transformation activities.

\section{Data analysis}

All qualitative data was analysed using thematic analysis (Coffey \& Atkinson, 1996) collected from the focus group, small group discussions and the workshops, using transcribed audio recordings. Analysis and coding of the transcripts was firstly performed by several academic staff, aided by NVivo $11 \mathrm{x}^{3}$, before being reviewed by all participants to confirm that themes captured reflected participants perceptions of experience. Participants and academics were provided with the transcripts and the analysis to familiarise themselves with the data prior to the workshops. We used workshop 2 and 3 to further refine or extend themes based on engagement in the dyads and experiences with the actionable projects (Braun \& Clarke, 2006). Prior to workshop 4, an independent staff member analysed all transcripts generated to that point, to ensure no key themes were missed. During Workshop 4, community of practice groups presented their work based on the actionable themes, after which a final round of analysis and sense making was conducted to collect the outcome data for the project. The research process used iterations of action and reflection, which created sustained engagement and critical reflexivity around the actionable themes and meaning making, trusting in the emergent nature of the process to discover and develop meaningful outcomes.

\footnotetext{
${ }^{3}$ NVivo is a qualitative data analysis computer software package
} 


\section{Results}

Data analysis generated three key themes of student concern 'getting into uni ${ }^{4}$ ', 'creating a sense of community' and 'quality learning and teaching'. In addition, for each theme, subthemes were identified, which are presented below.

\section{Theme 1: 'Getting into uni'}

\section{Administration processes: Participants} highlighted that they found university recruitment, admission and enrolment processes confusing and frustrating. Participants found the admission processes were unduly complex and lacked transparency. They also commented on the opacity of the selection criteria and admission processes, especially in highly competitive undergraduate courses. One explained that "they (student admissions) were very confused, there was no guidance, leaving students in a quandary" (student participant 3). Another reported that "they were not sure what to write in the personal competency statement" (student participant 4) and that "you're bombarded with so much that you miss eighty percent of the important stuff" (student participant 5).

Being new and not knowing: Participants described the anxiety of being new, having to deal with the overwhelming process of enrolment and starting their degree. They described 'not knowing' about many of the nuanced processes and that "often students don't know what they don't know, and you've actually got to go through that and hit the brick wall" (Student participant 6). However, they also highlighted how peer support aided in negotiating the process, "when we hear from seniors who have gone through that part, and they tell us, it's much more beneficial" and "networking plays a role in finding what your actual needs are" (student participant 2).
Orientation: Participants were motivated to attend the University orientation program, so they were well prepared for study and identified the value of this program for developing connections with their fellow students "for myself ... these are things I already knew. So, I just made friends on the first day" (student participant 9).

\section{Theme 2: 'Creating a sense of community'}

Student community: Participants spoke of their pride and of the privilege of being awarded a place to study with the University. Participants discussed at length, the importance of establishing relationships and social connections with staff and peers, one suggested that "engaging with other students is always important, knowing you're on the right track" (student participant 4). Others highlighted how being with peers on campus was beneficial, "when you're at home by yourself, or at the library, you don't know what everyone else is doing, no one to talk to or discuss your concerns" and "that face to face interaction is pretty important" (student participant 3) compared to the online environment.

Dealing with each other: Development of these important relationships were often undermined by the lack of engagement in class, age differences or lack of attendance by students due to time pressures of a fast track degree. Participants noted the challenge to learning of classmate's behaviour, especially around the use of social media in class, noting "...people are tapped on the shoulder (by other students) - like cut it out, it's really distracting, I tell them" (student participant 5).

Allocation of spaces: Importantly, participants noted a lack of spaces for social and cultural activities, and accommodation facilities, one articulated that "everyone is just coming into

4 "Uni" is the colloquial term used in Australia. We use this form when associated with student input. 
the class, there's actually no place to hang out" (student participant 8).

\section{Theme 3: Quality learning and teaching}

High expectations of academics: Participants challenged notions of quality in learning and teaching, engagement with students by academics, and the ability of tutors to manage the classroom interactions to maximise student learning. Participants had high expectations of staff, relying on the face-to-face contexts such as tutorials to mitigate being time-poor in the fasttrack programs. Participants demanded quality time with staff and expected high impact learning experiences. There was some dissatisfaction, for example, a student explained that "one of the tutors didn't really have the answer ... said go online, or you can make an appointment" (student participant 9). Participants expressed limited support for the blended learning environment in which lectures and resources are presented in an online learning management site. One participant noted, "I find it very hard to motivate myself to sit and watch an online lecture rather than actually going...I can't ask questions" (student participant 2).

Fast Track: Participants found that the concentrated nature of a fast track degree and lack of flexibility in timetabling was difficult to manage and had an impact on their learning and wider family life, one noting "you don't have a Christmas, cancel that" (student participant 7). This was especially so for students with work and family commitments and those with extensive travel time to/from campus in a large urban setting. "...sometimes it's like, well, I can go to work on a Wednesday and make some money at work and go to a two-hour lecture and travel four hours and - and lose money because I have to pay" (student participant 4).

Getting help: Participants highlighted need for support in adapting to university life. Many highlighted the lack of support with casual tutoring staff, noting “... the ones who are contracted, sometimes they just don't care". They noted the importance of relationships when seeking support "you might be spending some extra time, but that's the most effective way I've seen" (student participant 1) and that "teaching is a kind of relational practice" (academic participant 5).

\section{Discussion}

\section{What is meaningful for the first-year student?}

Underpinning each theme was the ability of the university staff to connect and engage with students to address their identified needs. James Cook University (2017) identified that 'there are various and obvious intervention points across the student lifecycle ... and we direct specific attention to enabling those transition phases' (p.3). The university's 'admission' processes were questioned owing to their lack of clarity - selection criteria not published, lack of confirmation emails, critical university dates not published, and no criteria for the personal competency statement - all resulting in confusion with admission and enrolment for students. Students' spoke of a common theme of "I did not know what I didn't know" with participants expressing frustration with the university's assumption that students knew all the facts. Allen (1999) argues that the first impression of a university may extrinsically motivate students to persist and Hughes and Smail (2015) suggest that complications and delays in admission processes should be minimised for first-year students. This stated confusion and conflicting expectations of the students in the study may have undermined student confidence and trust in the university. James Cook University's (2017) approach is to support students from the very start, through admission and enrolment, to make the processes seamless. 
Students identified opportunities to create learning communities as important, where peer relationships could thrive in a supportive environment. These learning communities were typically diverse, inclusive, and enabled connection, motivation and support through small classes and online. This learning community was asserted as fundamental to the development of the 'soft' people/social skills communication, listening, challenging, conflict management, empathy, and compassion required by health professionals. Students argued the need for dedicated social spaces "just to be with students" and feel part of the place. This issue was exacerbated for the students because the campus was a small satellite campus, had only been operating since 2008 and was not purpose built. Students helped inform the utilisation of space for planned renovations. Students identified several distinct cohorts for the university to acknowledge and plan for - school leavers and mature aged students, Australian, and CALD students. Group processes and strategies were needed to build engagement, inclusion, participation, and which acknowledge the diverse nature of the student cohort.

In the time-poor, fast-track programs, the role of the tutor and the tutor-student relationship were viewed as critical to the students' learning. Preparation and class engagement by tutors was valued, as was developing caring, motivating, inspiring, and/or passionate behaviours, and mutual trust. Kift et al. (2010), using a transition pedagogy conceptual model, reinforced the expressed student requirements: implementation of a curriculum that engages students in learning; proactive and timely access to learning and life support: intentional fostering of a sense of belonging; and the development of sustainable academicprofessional partnerships. Students were particularly critical when staff failed to provide direction, manage class dynamics and interactions, demonstrate professional behaviours and standards, encourage and facilitate debate with and between students, and promote interactions between different groups.

Students wanted tutors to promote peer interaction as a vehicle to support CALD students in their learning and teaching. The benefits of cultural diversity were recognised, particularly in promoting effective learning environments. The practise by tutors of using work experiences to frame learning was highly regarded, but students also wanted their experiences to contribute to learning, a view especially held by the mature aged students.

Creating a safe environment for students to take risks, to question and be vulnerable was regarded as central for student success. Staff communication with students, principally timely feedback, was perceived as an important source to motivate and improve teaching and the unit coordination. Students saw feedback best delivered person-to-person or in small groups, with questions encouraged.

\section{What guidance and support do first- year students need?}

To assist with the transition to university life and the migration to the world of the 'educated', four areas for guidance and support were identified by students: (1) the need for academic support to develop/enhance student wellbeing; (2) easing tensions with enrolment/admissions; (3) clarifying how units and courses link to learning, and (4) mitigating confusion associated with a new online learning system and timetable. James Cook University (2017) also acknowledged this critical concern, and have developed a College Support Officer, whose role is to interface between students and the discipline, guiding students to avoid ... "having to navigate often hard to penetrate processes, despite ... best efforts to the contrary" (p. 7).

Students also sought support for the establishment of peer mentoring groups and enabling the student 'voice', which included 
confidence to express opinion, thoughts and ideas in a safe learning space. This contrasted with the students' fear of embarrassment, or of not knowing. Students expressed concern of the stigma associated with seeking out academic learning support - especially for mature aged students, due to the fear of failure, and high expectations of family and friends and, in some circumstances, community expectations. Again, Porteous and Machin (2018) support this finding stating “... with positive supportive experience ... students develop resilience ... feel more confident and competent. Students expected and valued positive constructive feedback from tutors and mentors" (p.60).

CALD students had particular challenges such as adapting to new learning philosophies and environments, expressing themselves in English, and comprehending medical, anatomy and physiology terminology. CALD students expressed feelings of exclusion and disengagement, attributable to the overwhelming volume and pace of classes. Additionally, CALD students had difficulty adapting to new learning systems, university processes, student roles, attendance and expected behaviours in class. These findings are supported by Mitchell, Del Fabbro, and Shaw (2017) who identified "expressing myself" and "finding my place" as critical for international nursing students in Australia (p.18). Mitchell et al. (2017) identified group work to facilitate acculturation, language and learning, which are key to full participation in university life. CALD students also sought support and guidance to assist with the transition to university life, principally around cultural awareness/cultural safety, and otherness and discrimination (Mitchell, et al., 2017).

Students were aware of the impact and stress the fast-track program could have on them and their families, one noting "you don't need a Christmas tree for two years". Nevertheless, student participants in this group asserted that the benefits of achieving a health practitioner qualification in two years outweighed the social and emotional costs. Student support services were identified as the key to success in a fasttrack degree. Counselling in particular, was highly valued, providing financial advice, work/study/life balance support, and scholarship guidance. Whilst students identified that orientation/UniStart were important strategies to supplement the transition process, many stated that they were initially bombarded with too much information, with little time to absorb and integrate. Students recommended, "breaking it down, spacing it out, and repeating key information and skills". Many students viewed orientation week nonetheless, as a key time for getting to know their peers through networking activities and opportunities and to begin the transition process by experiencing a new start.

\section{Limitations of the research}

The primary limitation was the inherent power inequity between academics and students which potentially influenced interactions, responses and behaviours. To mitigate this, we paired students and academics from different programs and undertook sustained small group engagement over six months to allow relationships to form. Student workloads limited their available time, thus the academics had to carry primary responsibility for establishing and coordinating workshops, data collection and interpretation. Furthermore, the student participants comprised a small, selfselected group and hence, they may not have been representative of the wider student cohort. Further research is needed to extend the findings of this project with a larger cohort of students.

\section{Conclusion}

This research provided insights into the needs of first-year students in a small, urban satellite campus providing fast-track health discipline degrees. The research emphasised the need for providing opportunities to foster connection and engagement in the transition to university 
life; where students undergo a significant transition process, so they are empowered to become active learners. The research highlighted the notion that students should be co-creators of all aspects of learning, within a scholarly community, and ultimately develop an understanding of their own personalised learning. A relationally focused, whole student lifecycle approach to transition is required, so students connect and engage immediately with university structures. This can only be enabled by academic and professional staff who assist in navigating/guiding/supporting the student through what are at times complex and daunting processes. If successfully enabled, students are transformed. Their burden of learning is supported by a scholarly community, based on peer group and academic partnerships, where students are viewed as cocreators of learning and where student life is dynamic and vital. The project findings, although specific to a small cohort on a small campus, provide relevant insights into the firstyear experience as higher education expands and student cohorts become more diverse.

\section{References}

Allen, D. (1999). Desire to finish college: An empirical link between motivation and persistence. Research in Higher Education, 40(4), 461-485. doi:10.1023/A:1018740226006

Bramble, M., Maxwell, H., Einboden, R., Farrington, S., Say, R., Beh, C. L., . . . Rickard, G. (2018). Exploring and Improving Student Engagement in an Accelerated Undergraduate Nursing Program through a Mentoring Partnership: An Action Research Study. International Journal of Nursing Education Scholarship, 15(1). doi:10.1515/ijnes-2017-0090

Braun, V., \& Clarke, V. (2006). Using thematic analysis in psychology. Qualitative Research in Psychology, 3(2), 77-101. doi:10.1191/1478088706qp063oa

Bridges, W. (1986). Managing organizational transitions. Organizational Dynamics, 15(1), 24-33.

Briggs, A. R., Clark, J., \& Hall, I. (2012). Building bridges: understanding student transition to university. Quality in Higher Education, 18(1), 3-21. https://doi.org/10.1080/13538322.2011.614468
Brook, H., Fergie, D., Maeorg, M., \& Michell, D. (2015). Universities in Transition: Foregrounding Social Contexts of Knowledge in the First Year Experience (1st Edition ed.). Adelaide, Australia: University of Adelaide Press.

Burnes, B. (2004). Kurt Lewin and the planned approach to change: A re-appraisal. Journal of Management Studies, 41(6), 977-1002. doi:10.1111/j.14676486.2004.00463.x

Christie, H., Tett, L., Cree, V. E., Hounsell, J., \& McCune, V. (2008). 'A real rollercoaster of confidence and emotions': Learning to be a university student. Studies in Higher Education, 33(5), 567-581. doi:10.1080/03075070802373040

Coffey, A., \& Atkinson, P. (1996). Making sense of qualitative data: complementary research strategies. Thousand Oaks, CA: Sage Publications.

Gale, T., \& Parker, S. (2014). Navigating student transition in higher education: Induction, development, becoming. In Brook, H., Fergie, D., Maeorg, M., \& Mitchell, D (Eds.). Universities in transition: Foregrounding social contexts of knowledge in the first year experience, 13$39 . \quad$ Retrieved from https://www.adelaide.edu.au/press/titles/universit ies-transition/universities-transition-ebook.pdf

Heron, J., \& Reason, P. (1997). A participatory inquiry paradigm. Qualitative inquiry, 3(3), 274-294.

Hughes, G., \& Smail, O. (2015). Which aspects of university life are most and least helpful in the transition to HE? A qualitative snapshot of student perceptions. Journal of Further and Higher Education, 39(4), 466-480. https://doi.org/10.1080/0309877X.2014.971109

James Cook University. (2017). Student retention and success 2017: Not leaving student success to chance. Retrieved from https://studentretention.iqpc.com.au/downloads/ja mes-cook-university-not-leaving-student-success-tochance

Kift, S. (2009). Articulating a transition pedagogy to scaffold and to enhance the first year student learning experience in Australian higher education: Final report for ALTC senior fellowship program: Australian Learning and Teaching Council Sydney, Australia. Retrieved from http://transitionpedagogy.com/wpcontent/uploads/2014/05/Kift-Sally-ALTC-SeniorFellowship-Report-Sep-09.pdf

Kift, S. (2015). A decade of Transition Pedagogy: A quantum leap in conceptualising the first year experience. HERDSA Review of Higher Education, 2. 51-86. Retrieved from http://herdsa.org.au/herdsa-reviewhigher-education-vol-2/51-86

Kift, S., Nelson, K., \& Clarke, J. (2010). Transition pedagogy: A third generation approach to FYE: A case study of policy and practice for the higher education sector. 
The International Journal of the First Year in Higher Education, 1(1), 1-20. doi:10.5204/intjfyhe.v1i1.13

Mitchell, C., Del Fabbro, L., \& Shaw, J. (2017). The acculturation, language and learning experiences of international nursing students: Implications for nursing education. Nurse Education Today, 56, 16-22. doi: 10.1016/j.nedt.2017.05.019

Nelson, K., Duncan, M., \& Clarke, J. (2009). Student success: the identification and support of first year university students at risk of attrition. Studies in Learning, Evaluation, Innovation and Development, 6(1), 1-15. Retrieved from http://eprints.qut.edu.au/28064/

Polit, D. F., \& Beck, C. T. (2008). Nursing research: Generating and assessing evidence for nursing practice (8th ed.). Philadelphia, PA: Wolters Kluwer Health/Lippincott Williams \& Wilkins.

Porteous, D. J., \& Machin, A. (2018). The lived experience of first year undergraduate student nurses: A hermeneutic phenomenological study. Nurse Education Today, 60, 56-61. doi: 10.1016/j.nedt.2017.09.017

Smith, B. (2007). Accessing social capital through the academic mentoring process. Equity \& Excellence in Education, $\quad 40(1), \quad 36-46$. https://doi.org/10.1080/10665680601088465

Tinto, V. (1987). Leaving college: Rethinking the causes and cures of student attrition. Chicago, IL: University of Chicago Press.

Ward, C., Furnham, A., \& Bochner, S. (2005). The psychology of culture shock (2nd Edition ed.). Hove, UK: Taylor \& Francis Group.

Wenger, E. C., \& Snyder, W. M. (2000). Communities of practice: The organizational frontier. Harvard Business Review, 78(1), 139-146. Retrieved from https://hbr.org/2000/01/communities-of-practicethe-organizational-frontier

Wilson, K. L., Murphy, K. A., Pearson, A. G., Wallace, B. M., Reher, V. G. S., \& Buys, N. (2016). Understanding the early transition needs of diverse commencing university students in a health faculty: informing effective intervention practices. Studies in Higher Education, 41(6), 1023-1040. doi: $10.1080 / 03075079.2014 .966070$ 